\title{
8. Una pedagogía, más allá de nosotros mismos
}

DOI: https://doi.org/10.38017/9789588966458.08

Ernesto Hernández Barragán ${ }^{1}$

\subsection{El maestro-filósofo}

Filosofía: conocimiento por medio de conceptos; no otra es la definición de filosofía. El filósofo es aquel en quien el concepto está en potencia: realidad de lo virtual, o lo que es lo mismo el concepto se actualiza gracias a un obrar determinado de un filósofo: actualidad del concepto; de un lado, en su actualización, el concepto lleva una firma y el filósofo es determinado -el cogito y Descartes, el pliegue y Leibniz-, pero de otro lado, el concepto en su potencia, en su fuerza virtual permanece implicado, inexplicado, y el filósofo, "salido de sus goznes", se aboca a la paradoja, atravesado por el pathos, llevado al límite de sus facultades por el impulso de la "pasión de la filosofía", de tal manera que el pensamiento rompiendo sus lazos con lo posible alcanza el horizonte acontecimental en el que se implica e implica en su seno lo inexplicable, lo impensable. Transversal e inmanente a los planos filosóficos, científicos, artísticos, el concepto encuentra y construye resonancias y encuentros irreducibles a cada plano, resonancias y encuentros que son ocasión actual de experimentación por cuanto alcanzan, en la conjunción de planos y cada vez la máquina abstracta correspondiente.

1 Licenciado en Filosofía. Autor, editor y traductor de obras de filosofía contemporánea, entre ellas los libros: Manifiesto por la Universidad Nómada (con Carlos Enrique Restrepo. Medellín: Asoprudea, 2015); Lo social. Perspectivas anexactas (con Carlos Enrique Restrepo. Medellín: Endymión, 2014); Gilles Deleuze. Una vida filosófica (Cali: Sé Cauto \& Euphorion, 2004); Estética, pensamiento y vida (Cali: El Vampiro Pasivo, 1997); La revolución molecular (Cali: UniValle, 1994); El constructivismo guattariano (Cali: UniValle, 1993). Director de las revistas El vampiro pasivo y Sé cauto. Miembro de la Red Universidad Nómada.ehb_cali@yahoo.com 
Si bien el concepto, en su carácter paradójico, se ofrenda de un modo absoluto en una auto-posición en la que nada pre-existe, siendo su auto-posición la clave de su despliegue como creación, sentimos que en su devenir auto-posicionante, el concepto se encarna en momentos determinados, en tiempos específicos, en lugares localizados, en las gestas con las que el hombre, infinitamente maquinado, conjuga su naturaleza con la naturaleza para constituir una naturaleza de la naturaleza, compone sus fuerzas cósmicas con el cosmos alcanzando así zonas de la materia y del espíritu que no parecían tener lugar.

Conocer con todo el entendimiento posible. Adquirir el conocimiento gracias a la inteligencia, ésa es la operación del hombre en cuanto tal, pues no pertenece a nada de lo que está por encima o por debajo de él. Según Dante, la acción no es más que la extensión del conocimiento, y la existencia de una inmensa multitud de seres humanos se justifica por el hecho de que su número es necesario para actualizar siempre la posibilidad total del entendimiento humano (Rosselini, 1979, p. 60).

Así pues, el conocimiento por conceptos no es ajeno a una historia de la filosofía y esa historia es la de la sucesión de los sistemas, de tal manera que el concepto es conservado en el tiempo, así la historia de la filosofía construye un firmamento poblado por complejos sistemas que lo sideran y enmallan, constituyendo de ese modo los Universales en los que se sostiene el sueño ilusorio de reinar sobre las otras formas de conocimiento, aun presintiendo, pues en todas las filosofías anida esta inquietud, que ningún sistema en cuanto tal se cierra flanqueando de una vez por todas la línea de afuera con la que se enlaza lo imprevisto de una creación. Son estas las razones que tiene Nietzsche para oponerle al firmamento conceptual, al cielo pre-existente de los filósofos; le opone el aforismo como potencia intempestiva del concepto. Quizá cada vez que el firmamento se cierra en sí mismo y, por consiguiente, la filosofía llega a no tener ningún problema, a conciliarse con la época para constituir su identidad, es porque está por venir un nuevo movimiento, una nueva fuerza que hiende ese firmamento dejando entrar un poco 
de caos en estado puro, una fuerza caotizante. Latigazo de caos, chorro de caos en estado puro que arrastra al concepto fuera del tiempo histórico, poniéndolo en devenir, haciéndolo saltar fuera del sistema para ponerlo en relación de vecindad con los otros conceptos sobre el plano filosófico que adquiere de nuevo toda su potencia intensiva, su paradójico dinamismo espacio-temporal, destituyendo cualquier trascendencia. Ningún firmamento para los conceptos... el filósofo se aventura por el desierto protegido por una sombrilla -su pequeño firmamento- hecha jirones, desgarrada, hendida... No se trata de un caos indeterminista, indiferenciado e indiferente, puesto que al confrontarlo, necesariamente, se plantea la tarea de establecer un filtro, una criba, por la cual en el seno de la creación procesual, se alcanza la más pura ordenación, que corresponde, precisamente, a una multiplicidad en la que el ser es conexión, conjuntividad, mezcla, vecindad, o de lo contrario, al deshacerse la criba todo se hundiría, se hunde, se deshace en partículas-caos a velocidad infinita sin retorno ni forma, como cuando perdemos una idea que apenas llegada se deshace.

El filtro con el que medimos fuerzas para sacar algo del caos, está como en una especie de fuera de espacio, de fuera de tiempo. Todos los sistemas están poblados y son recorridos por esos movimientos intensivos que constituyen, precisamente, el campo trascendental real, el campo en el que el concepto es potencia virtual animando perpetuamente sus actualizaciones. Cada vez se despliega una nueva geografía sobre la que se distribuyen y recomponen sus relaciones, los diferentes planos para producir una nueva imagen del pensamiento. De tal modo cambia la naturaleza misma de la filosofía, debido a que ahora "la filosofía es devenir, no historia, coexistencia de planos no sucesión de sistemas" (Deleuze, 1993).

Ahora bien, ¿cómo orientarse en esta compleja coexistencia de planos para poder establecer la naturaleza y la potencia de cada concepto respecto de su historia, pero también respecto de su posición y de sus relaciones con los otros conceptos, de sus devenires o eventuales resurgimientos? He aquí la grandeza del filósofo: crear nuevos conceptos, tanto como la modestia de maestro, hacer la 
pedagogía del concepto. Modestia del filósofo: asumir la pedagogía del concepto, grandeza del maestro: arriesgarse en la creación de conceptos. Pues, es evidente que el filósofo tiene que hacer el concepto, el filósofo tiene algo por decir, tiene necesidad de decir ese algo, de hacer el movimiento infinito del concepto, hacerlo aparecer como un estado de cosas... entre tanto, el maestro asume la modesta tarea de explicarlo, de explicar el concepto, dotándolo ya no de un real, sino de la realidad de su relación con el presente, con los "dinamismos espacio-temporales".

Decimos maestro más bien que profesor, ya que el profesar tiene un carácter público mientras que el maestro tiene una tradición de artesanado, una especie de intimidad iniciática, de pericia, de larga preparación, como la larga trayectoria de un cometa. El profesor es detentador de las verdades de su tiempo, en conformidad con los poderes establecidos. El maestro es un cometa, que prepara y explica, por consiguiente usa conceptos que cambiarán la estabilidad de los saberes y llevarán a descubrir nuevos territorios en los que la época modificará su "voluntad de verdad", haciendo proliferar nuevas perspectivas, conjunciones y simbiosis inéditas entre los modos y maneras de conocer, de pensar. Del mismo modo, pensamos que, en la pedagogía del concepto, se requiere un discípulo: el que es impulsado a aprender, porque le es necesario, en lugar del alumno que solamente tiene avidez, cierta glotonería alimentaria.

En fin, hay una especie de doble vínculo maestro-filósofo presente a lo largo de la historia de la filosofía -con la extraordinaria excepción de Baruch de Spinoza-, que en los casos singulares se aboca a una experimentación colectiva en la que el maestro, como dice Jacques Ranciere, "disocia la maestría del saber", mientras el filósofo "enseña eso que aún no sabe", lo que está en proceso de crear. Acogiendo la multiplicidad de saberes y experiencias del discípulo, el maestro lo lanza en la aventura de relacionar su saber y experiencia con aquello que él ignora, mientras el filósofo lo arroja en plena mar forzándolo a pensar. Es necesario imaginar al filósofo también arrojado en aquello a lo que arroja al discípulo. Ranciére llega a decir que en el reparto de lo sensible se logra una ruptura o 
disociación entre, por una parte, la relación de voluntad a voluntad; $y$, por otra parte, la relación de inteligencia a inteligencia que se dan en toda relación maestro-discípulo.

Y esta disociación entre la voluntad que obliga a otra voluntad a querer saber y la disociación entre la inteligencia que aclara o explica a otra inteligencia, se obtiene en la medida en que el maestro tiene que deshacerse de cualquier contenido de saber. El maestro tiene que pasar por ser maestro ignorante. Y esta es su mayor astucia, su mayor provocación.

En cierto modo, ese maestro-filósofo es una especie de implacable provocador que enseña a no satisfacerse con lo que se sabe, que empuja siempre al discípulo a ser un buscador, un experimentador, mostrándole al discípulo que el saber magistral también es algo que siempre está en juego, en proceso de perderse o ganarse. En esencia, una pedagogía del concepto, sin renunciar al rigor del conocimiento y de la historia de la filosofía, cuenta fabulosas historias de poder, de potencia que se convierten en protocolos de experimentación para afirmar la disparidad, la diferencia, la potencia de creación de nuevos conceptos. Quizá la astucia del maestro-filósofo consiste en cierta mala voluntad y cierto mal humor para afirmar la diferencia en tanto que singularidad en el concepto como movimiento de la idea liberada de los "criterios de semejanza en la percepción, de la identidad en el concepto, de la analogía en el juicio, o de la oposición en el predicado" (Deleuze, 1988, p. 417). El maestro-filósofo no aspira, pues, a ser difundido, aspira a ser repetido, pero lo repetido no es el contenido de sus conceptos, ni la fría exhaustividad de la explicación, sino el movimiento de la implicación, de la diferencia, de la potencia de la que son portadores.

\subsection{El discípulo}

Es evidente que "no se aprende a nadar en seco", ninguna explicación colma el no saber como tampoco dota de capacidad alguna; por el contrario, es en la relación con el agua que el cuerpo se hace sensible a sus signos, de modo que al relacionarse con ese medio exterior 
sobre el cual se abre y en el cual actúa, selecciona el conjunto de signos con los que se compone para constituir un entre dos, una relación de implicación.

De igual manera, en una relación discipular no se trata de deshacer las posiciones respectivas de maestro a discípulo -que se encuentran racionalizadas por la distribución y asignación del conocimiento y la ignorancia en los términos definidos por la relación y en el que la relación misma se ha convertido en una finalidad-, como tampoco de que Maestro y discípulo intercambien posiciones revolucionando los dos en torno del centro, siempre esquivo, de la verdad, del ser. Quizá se trata más bien de crear una zona de indeterminación real, un afuera en el cual se compone la relación, en el que la relación se hace acontecimiento productor. Si bien el maestro no trasmite ningún conocimiento, más bien conecta $y$ hace circular una impulsión como el reto ante el cual el discípulo está, de entrada, descolocado, desencuadrado, -como en una experiencia de brujería, tal como lo ha mostrado Carlos Castaneda con su provocadora teoría del "punto de encaje" - y se ve obligado a alcanzar otras posiciones, de manera tal que el discípulo no se entrega al vano secreto dicho por la incertidumbre. El discípulo es como la rata en el laberinto, en el laboratorio, debe improvisar nuevas respuestas a nuevos estímulos. Recordemos que una de las reglas del sabio, según Sun Tzu, es la de acomodarse, con lo ya conocido, a los requerimientos del entorno, pero sin dejar que esa mecanización perturbe la flexibilidad de nuevos encuentros.

En esa zona de indeterminación real, el maestro, poseedor del saber, arriesga su saber en el límite de lo que no sabe, esa delgada línea entre lo que se sabe y lo que se ignora; y el discípulo ignorante (lo cual no quiere decir vacío, al contrario, lleno de una mezcla de ideas inadecuadas y nociones comunes), poseedor en potencia de ese saber, se aventura en el encuentro fortuito con el conocimiento. Si la filosofía necesita de un medio en el que no necesariamente estén determinados los personajes, tal determinación se alcanza con un trayecto o series de trayectos al final de los cuales se determinan los personajes. Si hay que orientarse en el pensamiento, y para 
orientarse es menester un mapa, todo mapa está hecho de devenires, de trayectos. Doble devenir en el que la implicación recíproca afecta por igual a maestro y discípulo haciendo de la pedagogía un agenciamiento: aventura de exploración del plano de consistencia pre-filosófico que habita el discípulo (en la relación intensiva de la filosofía con la no-filosofía) y del plano filosófico que habita el maestro y que se presuponen recíprocamente, pero esa exploración supone el concepto que ahora es dispuesto y cartografiado, dejando de ser abstracto, caótico, para devenir intensivo, relacional y creador, cósmico.

Pero no vamos a negar que los instantes de máximo valor vital son aquellos en que cuanto hacemos se ve vivificado por alguna clase de pensamiento que lo sustenta, un pensamiento recóndito que va más allá de nosotros mismos, a la vastedad de lo universal (Musil, 1992).

Experimentar la potencia del concepto, de su creación y recreación, sería aventurar un lanzamiento de dados agitados por la inminencia de la necesidad de pensar. Combinación extraña del azar y de la necesidad, el azar de lo que da que pensar con la necesidad de pensarlo, he ahí esa potencia siempre in nuce en el concepto, como la verdad eterna de su acontecer. La reciprocidad maestro-discípulo nada debe a la experiencia, que aquí es túmulo, memoria, como tampoco le debe nada a la inocencia ignorante que no es más que coquetería o abandono... Esta reciprocidad anuda su vínculo desigual y afirma su diferencia en la experimentación concebida como deriva, movimiento entre-dos, zona intermediara entre la intuición y la recepción, entre la espontaneidad del pensamiento y la receptividad inquietante del concepto, de tal manera que experimentar no es lanzarse al encuentro azaroso; requiere de un rigor, de un método y de una disciplina... experimentar es a una vida en tanto que deviene filosófica.

\subsection{El medio presente}

El oficio de hacer filosofía libera su carga potencial directamente como problema, construcción de problema, composición de un 
campo problemático que reclama un rigor y un estilo. Es lo que Deleuze y Guattari supieron reconocer al definir la filosofía esencialmente como un trabajo estético de creación, indisociable de una pedagogía del concepto. Crear en esta línea filosofante significa, de un lado, producir un real aquí y ahora, real que designa, como afirman Deleuze y Guattari, "esta conjunción de la filosofía o del concepto con el medio presente" (Deleuze, 1993), conjunción que se da en un espacio de conexiones intensas. Esta conjunción no se reduce a una coincidencia, es más bien un entrelazado, un vínculo, una operación de afirmación simultánea, pero en la cual el concepto no se confunde con el medio, actúa, hace máquina con él, lo modifica. Cópula del concepto con el medio, operación ilativa de consecuencias y condicionamientos recíprocos. No hay un objeto de la filosofía, hay un medio en el que todo deviene, y en el que el personaje conceptual, el personaje que pone en acción el concepto al mismo tiempo que lo afirma, deviene otra cosa que aquel del cual depende el pensar. Si miramos el devenir de la alquimia, que conducirá a la eclosión de la química, encontramos que esta tiene un medio antes de tener una historia, no obstante que los epistemológos le dan relevancia al carácter psicológico de aquello que ha sido puesto al margen por historiadores desatentos. "Pero, de atenernos a los historiadores, parece que los hechos se hubieran impuesto penosamente a pesar de las ideas, sin que se dé jamás una causa y una apreciación de esa resistencia. Los químicos del siglo XIX, llevados a juzgar el valor objetivo no han tomado en cuenta la notable cohesión psicológica de la cultura alquimista" (Bachelard, 1987, p. 55). Quizá en el medio, en cuanto inmanente, es donde se hacen indiscernibles el sujeto y el objeto revelando una tensión en la que la tierra traza las aventuras de todos los personajes que, con su talante, firmarán conceptos, los personajes conceptuales.

Ahora bien, esta conjunción de la filosofía con el medio presente no deja de correr riesgos, de enfrentar peligros, y estos peligros amenazan permanentemente con abatir la multiplicidad sobre una trascendencia cualquiera, o peor aún, lanzarla hacía una línea de abolición. Uno de los peligros y una gran dificultad de 
esta enunciación colectiva, en el poblamiento andino, en este sur americano, respecto de una filosofía, tiene que ver con la disyuntiva de una referencia exclusiva a Europa (o al otro-atlántico) o una recodificación discursiva a nombre de una homogenización identitaria -sea ella latinoamericana, sudaca, bolivariana u otra-. Peligro y dificultad que no podemos eludir a nombre de una universalidad de cierta filosofía o por el reconocimiento identitario de una subordinación del pensamiento a secularizaciones académicas. Se trata, entonces, en las difíciles condiciones que implican para la práctica filosófica las coacciones político-sociales, de re-crear, de usar -quizá para fines inconfesables-, en un "entre nosotros", la filosofía. Repoblar el plano, del que sin duda disponemos y sobre el cual se proyectan tantas figuras en su viaje teofánico, con una re-creación conceptual que sea provocación y devenir para el pensamiento en su intensa relación con la vida: una sophía que conjuga el bíos y el éthos en un renovado philos sobre el plano intenso de la vida. La tarea propiamente pedagógica responde entonces a la preocupación ético-estética y ético-política de “¿cómo orientarse en el pensamiento, en la filosofía?"

En el encuentro, modesto, insistente, en voz baja, que establecen maestro y discípulo en su mutua soledad, en su irrenunciable poblamiento, afirmando sus distancias, acordando de antemano una rigurosa discreción para el pensamiento, la filosofía, sus agentes y personajes, se lanzan en la tarea peligrosa de componer nuevos conceptos como estados de cosas; la filosofía ejerce un trastrocamiento de ese uso de la lengua como consigna del que nos habla Mil Mesetas, propiciando siempre nuevos agenciamientos de "subjetividad" como brotes de singularidad. Enfrentada a poderosos enemigos, la filosofía inventa su propia lengua minoritaria, menor, en lucha con el estilo prosaico y tecnocratizado, banalizante e infantilizante de los nuevos conceptuadores (la mercadotecnia, la lingüística, la publicidad, etc.), "rivales insolentes y bobos" (Deleuze y Guattari, 1993, p. 17) que florecen a la sombra del capital. 


\subsection{El lugar del encuentro}

El encuentro entre maestro y discípulo tiene lugar y tiene un lugar, lugar del encuentro fortuito en el que se sella una alianza abierta a los encuentros y liberada de las influencias; quizá, es de esta manera cómo podemos calificar los nuevos espacios en los que se agencia, hoy en día, la filosofía. Del aula al libro y a la revista institucional y de estos a la revista efímera, los blogs, los sites de filósofos e iniciados, de profes y grupos confesionales, iniciados y resistentes, el lugar del encuentro se ha modificado tanto como las formas por las que pasaba la filosofía, puesto que la forma privilegiada del libro ahora se conjuga con formas menos totalizantes, fragmentarias, ilocalizables. Sin duda, el libro ha cambiado de naturaleza, ya no reina como unidad cerrada que enuncia un sistema o que es pieza de un sistema en sí mismo cerrado, se abre sobre relaciones de vecindad y de distancia que hacen multiplicidad, de tal manera que la interpretación-comentario no resuena en el interior del sistema. Del mismo modo, el libro, ahora atravesado por corrientes de aire venidas de todas partes, se inscribe sobre movimientos ya existentes como pieza de nuevas pequeñas armas atómicas. Es en este sentido que en el ámbito académico Ranciére propone, en El Maestro Ignorante, un rompimiento con lo que impide la libertad expresión del discípulo. Ranciére dice que, con la transmisión del saber, el maestro impone su voluntad a la del discípulo. Y esto se hace dentro de un círculo vicioso. Es la explicación lo que hace que el discípulo se dote de saber, suprima su distancia con lo que no sabe. "Explicar es disponer los elementos del saber por transmitir en conformidad con las capacidades supuestamente limitadas de los espíritus por instruir" (Rancière, 2002). La explicación está en los libros. Pero los libros, en el sistema de trasmisión del saber, deben ser explicados por el maestro. La explicación se acompaña generalmente por una explicación de la explicación; los libros se necesitan para explicar a los discípulos el saber por aprender. Pero esto es insuficiente, puesto que son necesarios los maestros para explicar los libros que explican el saber a los discípulos. Siempre se requiere una explicación demás, para que el discípulo ignorante pueda retener aquello que tiene que comprender para saber. 
Solo cuando el maestro tiene la modestia de ser ignorante, puede enseñar algo que el discípulo también ignora. Y esto lo logra el maestro cuando entra en un medio en que la explicación de la explicación de la explicación se rompe en provecho de un acentramiento de la explicación redoblada, pero ya suficiente en su carácter de búsqueda. La interpretación de interpretaciones pasa entonces por un sistema de automatismos acentrados, rizomáticos, en el que cada punto tiene que ver con cualquier otro punto y la ilación es siempre un entre-dos: inmensa lanzadera que arrastra el pensamiento por fuera de sus lugares comunes o que hace de los lugares comunes espacio-tiempos singulares en los que se producen los nuevos encuentros, nuevos encuentros productores de nuevas imágenes del pensamiento. La unidad abierta maestro-discípulo conjuga sus potencias, en el campo rizomático poblado de nuevas relaciones y de nuevas relaciones de relaciones, con el no-filósofo para re-construir la consistencia de los conceptos y dotar de una nueva potencia de resistencia y acción al filósofo en su relación con la tierra -plano de los planos-. Líneas y velocidades, en medio de los medios, la filosofía viaja de nuevo y en ese viaje encuentra, descubre y crea un nuevo medio, reinventa una pragmática, crea un método transversalista, con el que y en el que de nuevo es posible una pedagogía.

\section{Referencias}

Bachelard, G. (1987). La formación del espíritu científico. Siglo XXI Editores.

Deleuze, G. (1988). Diferencia y Repetición. Jucar Universidad.

Deleuze, G., y Guattari, F. (1993). ¿Qué es la filosofía? Anagrama.

Musil, R. (1992). Ensayos y Conferencias. La Balsa de la Medusa.

Ranciére, J. (2002). El Maestro Ignorante. Editorial Laertes.

Rossellini, R. (1979) Un espíritu libre no debe aprender como esclavo. Editorial Gustavo Gilli. 